\title{
Endophytic taxol-producing fungi from bald cypress, Taxodium distichum
}

\author{
Jia-yao Li, ${ }^{1}$ Gary Strobel, ${ }^{1}$ Rajinder Sidhu, ${ }^{2}$ W. M. Hess ${ }^{3}$ \\ and Eugene J. Ford ${ }^{1}$
}

Author for correspondence: Gary Strobel. Tel: +1406994 5148. Fax: + 14069941848.

\footnotetext{
1 Department of Plant Pathology, Montana State University, Bozeman, MT 59717, USA

2 Cytoclonal Pharmaceutics, 9000 Harry Hines Blvd, Dallas, TX 75235, USA

3 Department of Botany \& Range Science, Brigham Young University, Provo, UT 84602, USA
}

\author{
Pestalotiopsis microspora occurs as a range of strains in bald cypress, \\ Taxodium distichum. The organisms live as endophytes in the bark, phloem \\ and xylem, and isolates show differences in cultural and microscopic \\ characteristics on common laboratory media. Many of these fungi make taxol \\ as determined by the reactivity of partially purified culture extracts with \\ specific monoclonal antibodies against taxol. In the case of one strain of $P$. \\ microspora (CP-4), taxol was isolated from culture medium and was shown to \\ be identical to authentic taxol by chromatographic and spectroscopic means.
}

Keywords: taxol, Pestalotiopsis microspora, anticancer drugs, endophytic fungi, Taxodium distichum

\section{INTRODUCTION}

Taxodium disticbum (L.) Rich (bald cypress) is a tall $(30-40 \mathrm{~m})$ coniferous tree typically growing in swamps, where it forms extensive pure stands. Its location is primarily in the SE United States (Harlow \& Harrar, 1950). Taxus (yew), the source of the anticancer drug, taxol, belongs to the plant family Taxaceae, is also a conifer and grows in similar habitats to bald cypress (Harlow \& Harrar, 1950; Hartzell, 1991). Both genera are evergreens with linear two-ranked leaves and both prefer damp environments. It is conceivable that the taxol in Taxus spp. may serve as a protective measure to the tree, given its effectiveness against the phycomycetous fungi Pythium and Phytophtbora, which can cause pathological problems to roots of some plant species in damp environments (Young et al., 1992). It is now known that several endophytes of Taxus spp. also produce taxol (Stierle et al., 1993, 1994; Strobel et al., 1996).

The acquisition of the metabolic machinery to produce taxol, either by coevolution or by genetic transfer, by these endophytes may enable them to better compete in their environment (Young et al., 1992). Given the enormous reproductive potential of these fungi via spore formation, it is conceivable that taxol-producing endophytes might be found in plants not making taxol, but having a similar ecology to Taxus. Thus, our rationale was to search the swamps of the southern United States for such plants. The evergreens most resembling Taxus, but not producing taxol, are bald cypress $-T$. disticbum and its relatives. Sampling a few limbs of this tree yielded many strains of endophytic Pestalotiopsis microspora, some of which produced taxol. Thus, this report provides evidence of taxol production by fungi not associated with a plant that makes taxol, and indicates that other plant species residing in certain damp environments may also be hosts to such taxol-producing endophytes.

\section{METHODS}

Sampling of $T$. distichum. Samples of T. distichum were obtained several miles inland, in a swamp forest, from the central coast of South Carolina at the coordinates N $32^{\circ} 52^{\prime} 267^{\prime \prime}$ and W $80^{\circ} 05^{\prime} 334^{\prime \prime}$. We harvested seven terminal twig samples $(0.5-1 \mathrm{~cm} \times 20 \mathrm{~cm})$ from a relatively young tree $7 \mathrm{~m}$ high. The samples were immediately transported to our laboratory in Montana and stored at $6{ }^{\circ} \mathrm{C}$ until being processed a few days later.

Endophytes of $\boldsymbol{T}$. distichum. These fungi were isolated from the sterilized outer bark ( $\mathrm{Cb}$ designation), the phloem/cambium (Cp designation) and the xylem ( $\mathrm{Cx}$ designation). The stem fragments were surface-sterilized with $70 \%(\mathrm{v} / \mathrm{v})$ ethanol, then each layer of tissue was sampled with a sterilized sharp blade. Small pieces of plant tissue were excised and placed on water agar in Petri plates. After several days, individual hyphal tips of the fungal colonies were removed and placed on potato dextrose agar (PDA), incubated for $10 \mathrm{~d}$, and periodically checked for culture purity. Eventually, each culture type was again transferred, by the hyphal tip method, to a water agar plate containing small pieces of sterilized carnation leaves. These gammairradiated leaves commonly permit the development of fungal fruiting structures which aid in their identification (Nelson $e t$ al., 1983). The fungal isolates were numbered and stored in distilled $\mathrm{H}_{2} \mathrm{O}$ at $4{ }^{\circ} \mathrm{C}$ as agar plugs or in $15 \%(\mathrm{v} / \mathrm{v})$ glycerol at $-70^{\circ} \mathrm{C}$ as spores and mycelium. 
Fungal identification by microscopy. Fungal spores and fruiting bodies appearing on the carnation leaf fragments were examined by stereo and light microscopy for measurement and identification. Reference strains from the Centraalbureau voor Schimmelcutures, Baarn, The Netherlands, were used for comparison. Comparisons of culture characteristics were made by standard methods after growing the organisms on PDA at $23{ }^{\circ} \mathrm{C}$. Fruiting structures were fixed and processed using the methods of Upadhyay et al. (1991), except that they were placed in $2 \%(\mathrm{v} / \mathrm{v})$ glutaraldehyde in $0 \cdot 1 \mathrm{M}$ sodium cacodylate buffer (pH 7.2).

Fungal culturing and taxol isolation. The fungi were grown in 2-litre Erlenmeyer flasks containing $500 \mathrm{ml}$ MID medium supplemented with $1 \mathrm{~g}$ soytone $1^{-1}$ (Strobel $e$ t al., 1996). After 3 weeks of still culture at $23{ }^{\circ} \mathrm{C}$, the culture fluid was passed through four layers of cheesecloth to remove solids and the preparation was treated as previously described (Strobel $e t$ al., 1996). After methylene chloride extraction the extract of each fungal isolate was examined for the presence of taxol by an immunological method. In the case of one isolate, CP-4, we obtained at least 101 of culture fluid and then isolated and purified the taxol present in the fluid by standard methods (Strobel $e t$ al., 1996). This fungus was chosen for taxol isolation because of its relatively high production of taxol as determined immunologically on culture extracts.

TLC. All comparative TLC analyses were carried out on Merck $0.25 \mathrm{~mm}$ silica gel plates developed in the following solvents: A, chloroform/methanol $(7: 1, \mathrm{v} / \mathrm{v}) ; \mathrm{B}$, chloroform/acetonitrile $(7: 3, \mathrm{v} / \mathrm{v}) ; \mathrm{C}$, ethyl acetate/2-propanol $(95: 5, \mathrm{v} / \mathrm{v}) ; \mathrm{D}$, methylene chloride/tetrahydrofuran $(6: 2, \mathrm{v} / \mathrm{v})$; and $\mathrm{E}$, methylene chloride/methanol/dimethylforamide ( $90: 9: 1$, by vol.). Taxol was detected using a spray reagent consisting of $1 \%$ vanillin $(\mathrm{w} / \mathrm{v})$ in sulfuric acid after gentle heating (Cardellina, 1991). It appears as a bluish spot fading to dark grey after $24 \mathrm{~h}$.

HPLC. We used a taxsil column $(4.6 \times 250 \mathrm{~mm}$; Metachem Technologies) for determining the behaviour of putative fungal taxol by HPLC. Samples in $10 \mu \mathrm{l}$ of methanol were injected and elution was done isocratically with methanol/ $\mathrm{H}_{2} \mathrm{O}$ (66:34, $\mathrm{v} / \mathrm{v})$. A variable-wavelength recorder set at $235 \mathrm{~nm}$ was used to detect compounds eluting from the column.

Spectroscopic analyses. After isolation from fungal cultures, the putative taxol was dissolved in $100 \%$ methanol and examined with a Beckman D-50 spectrophotometer. Electrospray mass spectroscopy was done on samples dissolved in methanol $/ \mathrm{H}_{2} \mathrm{O} /$ acetic acid $(50: 50: 1$, by vol.). It was injected with a spray flow of $2 \mu \mathrm{min}^{-1}$ with a spray voltage of $2 \cdot 2 \mathrm{kV}$ by the loop injection method.

Taxol immunoassays. A fungal extract was dissolved in methanol at $50 \mathrm{mg} \mathrm{ml}^{-1}$. The insoluble materials were removed by centrifugation in a microfuge for $10 \mathrm{~min}$. Taxol in samples was assayed by competitive inhibition enzyme immunoassay (CIEIA) method (Grothaus et al., 1993). The assay was carried out using a taxol immunoassay kit (Hawaii Biotechnology Group) according to the procedure recommended by the suppliers. In brief, this assay was performed in a 96-well microtitre plate coated with taxol-protein coating antigen. The plate was blocked with $1 \%(\mathrm{w} / \mathrm{v})$ BSA in PBS. After washing, the solid-phase-bound taxol was incubated with samples and taxol standards and a specific antitaxol monoclonal antibody. The taxol in the sample competes with solid-phase-bound taxol for binding to the monoclonal antibody. The monoclonal antibody bound to the solid-phase-bound taxol was detected by an alkaline-phosphatase-conjugated second antibody and alkaline phosphatase substrate, $p$-nitrophenol phosphate. The inhibition of colour development was proportional to the concentration of free taxol present in samples. The amount of taxol in each sample was calculated from an inhibition curve made by using different concentrations of standard taxol supplied with the kit. We used this technique to screen for taxol in each of the fungal extracts. The assay is sensitive to about $1 \mathrm{ng} \mathrm{ml^{-1 }}$.

Materials. All solvents used for TLC and HPLC were HPLCgrade solvents; those used for extraction were ACS grade. Taxol used for reference purposes was a generous gift of the National Cancer Institute.

\section{RESULTS AND DISCUSSION}

\section{Endophytic fungi}

From seven limb pieces of bald cypress that were sampled, we recovered 21 endophytes, 16 of which were identified as Pestalotiopsis microspora (Speg.) Bat. \& Peres. (Table 1). Typically, each individual isolate produced, on carnation leaves, conidiomata containing numerous conidia. The conidia were fusiform, possessing four septa with hyaline basal and terminal cells, with a brownish coloration in the median cells. The conidia had three or four characteristic terminal cell appendages (Strobel et al., 1996). The conidia from each of the $P$. microspora strains generally averaged $6-7.6 \mu \mathrm{m} \times 18.7-28.8 \mu \mathrm{m}$ in size when obtained from the carnation leaves (Table 1). Each of the isolates had spore sizes, shapes and coloration typical of $P$. microspora (Table 1).

Two of the other endophytes recovered from the limb pieces samples in this study were pycnidia formers making no taxol. They were studied no further.

Culturing of the Pestalotiopsis strains on a number of common laboratory media revealed that each had more or less distinctive cultural features. These were carefully noted using standard macromorphological characteristics after growth on PDA for $7 \mathrm{~d}$ at $23^{\circ} \mathrm{C}$. Of the strains of Pestalotiopsis shown in Table 1 , with two exceptions, each was distinctive in some manner from the others listed. Only two isolates, $\mathrm{Cb}-8$ and $\mathrm{Cb}-5$, were identical in all respects. These characteristics were maintained after each of several transfers on PDA and other common laboratory media. However, with the other isolates listed, variation was noted in surface texture, colour (bottom of the culture), shape of the surface mycelia, zonation ridging or furrows, and sectoring (Table 1).

The behaviour of $P$. microspora (Cp-4) spores under different conditions of development, humidity and processing was also noted. Characteristically, when the conidia of $P$. microspora were formed they were turgid, but as cultures dried, conidia, both in leaf tissue and on the culture media, shrivelled. When placed in distilled water the conidia became turgid in a few seconds. However, in spore mounting media it took $1-2 \mathrm{~h}$ for spores to become turgid. Spores from dried cultures often burst after 10-15 min in distilled water. In light microscopic sections young developing conidia characteristically appeared turgid, and older spores, even on the same leaf tissue, were normally shrivelled. These same observations were 
Table 1. Cultural characteristics of the $P$. microspora endophytes of $T$. distichum

\begin{tabular}{|c|c|c|c|c|c|c|c|c|}
\hline $\begin{array}{l}\text { Fungal } \\
\text { strain* }\end{array}$ & $\begin{array}{c}\text { Top surface } \\
\text { texture }\end{array}$ & $\begin{array}{l}\text { Bottom } \\
\text { colour }\end{array}$ & $\begin{array}{l}\text { Colony } \\
\text { shape }\end{array}$ & Zonationt & Furrows $†$ & $\begin{array}{c}\text { Taxol } \\
\left(\text { ng } 1^{-1}\right)\end{array}$ & Sectors $†$ & $\begin{array}{l}\text { Mean spore } \\
\text { size }(\mu \mathrm{m}) \ddagger)\end{array}$ \\
\hline $\mathrm{Cp}_{\mathrm{p}} 4$ & Tufted & $\begin{array}{l}\text { Tan/brown } \\
\text { sectors }\end{array}$ & Plateau & $\mathrm{N}$ & $\mathrm{N}$ & 1487 & $\mathrm{Y}$ & $19.52 \times 6.08$ \\
\hline$C x-2$ & Tufted & Tan & Concave & $\mathrm{Y}$, coarse & $\mathrm{N}$ & 498 & $\mathrm{~N}$ & $18.72 \times 5.92$ \\
\hline Cp-2 & Tufted & Brown & Plateau & $\mathrm{N}$ & $\mathrm{N}$ & 116 & $\mathrm{~N}$ & $26 \cdot 40 \times 7 \cdot 04$ \\
\hline $\mathrm{Cb}-4$ & Tufted & Tan & Plateau & $\mathrm{N}$ & $\mathrm{N}$ & 99 & $\mathrm{~N}$ & $22.40 \times 7 \cdot 04$ \\
\hline Cp-10 & Tufted & $\begin{array}{l}\text { Tan centre/ } \\
\text { velvety margin }\end{array}$ & Concave & $Y$, coarse & Y & 85 & $\mathrm{~N}$ & $24 \cdot 80 \times 7 \cdot 44$ \\
\hline Cp-6 & Tufted & Tan & Convex & $\mathrm{N}$ & $\mathrm{N}$ & 82 & $N$ & $26 \cdot 24 \times 6 \cdot 40$ \\
\hline $\mathrm{Cb}-2$ & Tufted & $\begin{array}{l}\text { Brown centre/ } \\
\tan \text { margin }\end{array}$ & Concave & $\mathrm{N}$ & $\mathrm{N}$ & 59 & $\mathrm{~N}$ & $24.32 \times 6.88$ \\
\hline Cp-1 & Tufted & $\begin{array}{l}\text { Brown centre/ } \\
\text { tan margin }\end{array}$ & Convex & $\mathrm{N}$ & $\mathrm{N}$ & 24 & $\mathrm{~N}$ & $24 \cdot 16 \times 7 \cdot 20$ \\
\hline $\mathrm{Cx}-1$ & $\begin{array}{l}\text { Velvety } \\
\text { centre/ } \\
\text { tufted margin }\end{array}$ & Tan & Concave & $Y$, coarse & $\mathrm{N}$ & 14 & $\mathrm{~N}$ & $23.52 \times 7.52$ \\
\hline $\mathrm{Cp}^{-7}$ & Tufted & $\begin{array}{l}\text { Tan margin/ } \\
\text { yellow centre }\end{array}$ & Concave & $\mathrm{N}$ & $\mathrm{Y}$ & 0 & $\mathrm{~N}$ & $26.56 \times 6.80$ \\
\hline Cp-5 & Tufted & $\begin{array}{l}\text { Tan margin/ } \\
\text { brown centre }\end{array}$ & Concave & $Y$, coarse & $\mathrm{N}$ & 0 & $\mathrm{~N}$ & $24.16 \times 6 \cdot 72$ \\
\hline $\mathrm{Cb}-3$ & Tufted & $\begin{array}{l}\text { Tan margin/ } \\
\text { yellow/white }\end{array}$ & Concave & $Y$, coarse & $\mathrm{N}$ & 0 & $\mathrm{~N}$ & $25 \cdot 76 \times 7 \cdot 28$ \\
\hline$C x-4$ & Tufted & Tan & Concave & $\mathrm{N}$ & $\mathrm{N}$ & 0 & $\mathrm{Y}$ & $21.28 \times 6.56$ \\
\hline $\mathrm{Cp}_{\mathrm{p}} 8$ & Velvety & Brown & Convex & $\mathrm{N}$ & $\mathrm{N}$ & 0 & $\mathrm{~N}$ & $28.80 \times 6.48$ \\
\hline $\mathrm{Cb}-8$ & Tufted & Tan uniform & Concave & $\mathrm{N}$ & $N$ & 0 & $\mathrm{~N}$ & $24.32 \times 6.80$ \\
\hline $\mathrm{Cb}-5$ & Tufted & Tan uniform & Concave & $\mathrm{N}$ & $\mathrm{N}$ & 0 & $\mathrm{~N}$ & $24.16 \times 6 \cdot 72$ \\
\hline
\end{tabular}

* The isolation site of the strains is designated as follows: $\mathrm{Cb}$, outer bark; $\mathrm{Cp}$, phloem/cambium; $\mathrm{Cx}$, xylem.

$\dagger \mathrm{N}$, no; $\mathrm{Y}$, yes.

$\ddagger$ Measurements were made on at least 10 spores per photograph. The spores were obtained from sterilized, inoculated carnation leaves. For comparative purposes, note that CBS isolate 790.68 of $P$. microspora has a mean spore size of $25.76 \times 6.72 \mu \mathrm{m}$, and CBS isolate 332.76 has a size of $20.00 \times 5.04 \mu \mathrm{m}$.

also made with tissues processed for SEM. However, newly developed spores remained turgid although the hyaline apical and basal cells sometimes shrivelled. Although some studies have been done on the ultrastructural characteristics of Pestalotiopsis (Sun et al., 1990; Purokit \& Chawla, 1989), none seem to have observed this behaviour of conidiospore shrinkage and swelling.

\section{Taxol from endophytes}

An enormous variation was noted in taxol production by the Pestalotiopsis strains as measured by the immunological assay (Table 1). This variation in taxol production of Pestalotiopsis will offer an important tool in unravelling the molecular biology of taxol producing fungi via mRNA differential display techniques (Liang et al., 1993).

As a further check on validity of the immunoassay, we chose to isolate and characterize taxol from the highly productive taxol strain Cp-4 (Table 1). We prepared 101 of 3-week-old culture fluid and processed it as described by Strobel et al. (1996). The compound that was isolated, in microgram quantities, possessed identical chroma- tographic properties in all TLC systems (A-E), and yielded an identical colour reaction, to authentic taxol. It was never seen in uninoculated culture media and could not have been carried from the original source tree, since taxol is not present in bald cypress. This fact was established after we exhaustively extracted $5 \mathrm{~g}$ of cut leaves and twigs of bald cypress with methylene chloride and subjected the residue to the immunological analyses, which gave negative results.

The fungal compound produced an identical electrospray mass spectrum as authentic taxol, with the major molecular ion being $(M+\mathrm{Na})^{+}=876$ (McClure et al., 1992; Stierle et al., 1993). The $(M+\mathrm{H})^{+}$peak was not observed either with authentic taxol or with the fungal preparation. Furthermore, the compound from the fungus yielded a $\mathrm{UV}$ absorption spectrum identical to that of authentic taxol (Wani et al., 1971). We also observed that the fungal compound gave a single peak when eluting from the taxsil HPLC column, with about the same retention time as authentic taxol. When authentic taxol, in equimolar amounts, was co-chromatographed with the fungal compound only a single peak appeared, having a retention of 
25.8 min. The combined immunochemical, chromatographic and spectroscopic data suggest that the fungal compound is taxol.

\section{Conclusions}

The observations presented in this report strongly suggest that plants other than yew may be a source of microbes producing taxol. An examination of Western red cedar, Thuja plicata, a common species in the canopies of Western yew forests, for $P$. microspora and other endophytes has yielded only a few microbes and no Pestalotiopsis spp. (G. Strobel, unpublished). Seemingly the cedars are not a reservoir for the microbes of yew even though their large size and predominance in the locales common to the yews would expose them to the same spectrum of fungi.

There is no doubt that $P$. microspora strain $\mathrm{Cp}-4$ makes taxol. However, this strain also is one that frequently makes sectors on PDA plates, indicating that it is genetically unstable. This fact may account for the wide range of taxol production observed from this isolate, varying from 50 to $1487 \mathrm{ng} \mathrm{l}^{-1}$ (J. Li \& R. Sidhu, unpublished). This sectoring phenomenon seems to be relatively uncommon among the other isolates of $P$. microspora (Table 1).

We also speculate that $P$. microspora and other species of the Pestalotiopsis/Pestalotia complex may be an extremely genetically flexible group, as manifested by their large variation in cultural characteristics and taxol production (Table 1). This flexibility might be related to their peculiar cell morphology and their ability to respond dramatically to environmental conditions. Such responses may represent a ready exchange of genetic information allowing this organism to mimic the chemical environment of its host and, ultimately to gain a number of evolutionary advantages.

\section{ACKNOWLEDGEMENTS}

The authors wish to thank Suzan Strobel for her assistance in collecting tree samples. Ms Donna Garton Kenney did the HPLC analyses. Mr Mike Standing assisted with the SEM work. Dr Kathy Cripps and Dr David Long helped to identify fungal culture characteristics. Dr Joe Sears, of the Montana State University Department of Chemistry \& Biochemistry, kindly did the electrospray mass spectroscopy work. Financial help was provided by NCI grant ROI CA 58315-03, Cytoclonal Pharmaceutics, Inc., and the Montana Agricultural Experiment Station.

\section{REFERENCES}

Cardellina, J. H. (1991). HPLC separation of taxol and cephalomannine. J Liq Cbromatogr 14, 659-665.

Grothaus, P. G., Raybould, T. J. G., Bignami, G. S., Lazo, C. B. \& Byrnes, J. B. (1993). An enzyme immunoassay for the determination of taxol and taxanes in Taxus sp. tissues and human plasma. $J$ Immunol Methods 158, 5-15.

Harlow, W. M. \& Harrar, E. S. (1950). Textbook of Dendrology. New York: McGraw-Hill.

Hartzell, H. (1991). The Yew Tree. Eugene, OR: Hugolosi Press.

Liang, P., Avenbourk, L. \& Pardee, A. B. (1993). Distribution and cloning of eukaryotic $\mathrm{mRNAs}$ by means of differential display: refinements and optimization. Nucleic Acids Res 21, 3269-3275.

McClure, T. D., Schram, K. N. \& Reimer, M. L. J. (1992). The mass spectroscopy of taxol. Am Soc Mass Spectrom 3, 672-679.

Nag, T. R. (1993). Coelomycetous Anamorphs with Appendage Bearing Conidia. Waterloo, Ontario: Mycologue Publications.

Nelson, T. A., Toussoun, T. \& Marasas, W. F. O. (1983). Fusarium Species. University Park, PA: Penn State University Press.

Purohit, D. K. \& Chawla, G. C. (1989). Fine structure of conidia in two pathogenic species of Pestalotiopsis. Curr Sci 58, 659-665.

Stierle, A., Strobel, G. \& Stierle, D. (1993). Taxol and taxane production by Taxomyces andreanae, an endophytic fungus of Pacific yew. Science 260, 214-216.

Stierle, A., Stierle, D., Strobel, G., Bignami, G. \& Gothaus, P. (1994). Bioactive metabolites of the endophytic fungi of Pacific yew, Taxus brevifolia. In Taxane Anticancer Agents, Basic Science Current Status (American Chemical Society Symposium Series, no. 583), pp. 81-97. Edited by G. I. Georg, T. T. Chen, I. Ojima \& D. M. Vyas. Washington, DC: American Chemical Society.

Strobel, G. A., Yang, X., Sears, J., Kramer, R., Sidhu, R. \& Hess, W. M. (1996). Taxol from Pestalotiopsis microspora, an endophytic fungus of Taxus wallacbiana. Microbiology 142, 435-440.

Sun, X. A., Ge, Q. X. \& Ling, H. Z. (1990). Studies on the criteria of morphological characteristics for species classification of Pestalotiopsis. I. A brief review of nomenclature for the genus Pestalotiopsis and observations on conidia of Pestalotiopsis by SEM. Acta Agric Univ Zhejiangensis 16 (Suppl. 2), 168-172.

Upadhyay, R. K., Strobel, G. A. \& Hess, W. M. (1991). Morphogenesis and ultrastructure of the conidiomata of Ascocbyta cypericola. Mycol Res 95, 785-791.

Wani, M. C., Taylor, H. L., Wall, M. E., Coggen, P. \& McPhail, A. T. (1971). Plant antitumor agents. VI. The isolation and structure of taxol, a novel antileukemic and antitumor agent from Taxus brevifolia. J Am Chem Soc 93, 2325-2327.

Young, D. H., Michelotti, E. J., Swindell, C. S. \& Krauss, N. E. (1992). Antifungal properties of taxol and various analogues. Experientia 48, 882 885.

Received 29 December 1995; revised 1 April 1996; accepted 9 April 1996. 